\title{
On the Relationship Between First Occupation and Current Occupational Status
}

\author{
E. M. BECK \\ Department of Sociology \\ University of Michigan \\ with \\ J. H. MADANS \\ Department of Sociology \\ University of Michigan
}

I

nterest in the status attainment process is of comparatively recent vintage, yet the literature on this topic is voluminous. Primarily this research has concentrated on determining the relative effects of socioeconomic background variables upon occupational status at various points in the work career. One major portion of this research has been directed toward discovering the factors responsible for early occupational attainment (e.g., Sewell, Haller, and Portes, 1969), while the other thrust has been toward identifying the

Authors' Note: Support for this research was provided by Public Health Service Research Grant MH.19689 from the National Institute of Mental Health and the Office of Economic Research, Economic Development Administration, Grant OER-417-G-72-7 to Gene F. Summers. We wish to acknowledge the comments of R. Melville Cohn, G. F. Summers, and William Mason.

SOCIOLOGY OF WORK AND OCCUPATIONS, VoI. 1 No. 4, November 1974 (C) 1974 Sage Publications, Inc. 
determinants of occupational status during later periods of the career.

A large part of Blau and Duncan's (1967) seminal analysis, for example, examines the social influences on "current" occupational attainment (as of 1962). Since the respondents in Blau and Duncan's "OCG" data entered the labor force at different times, "current" occupation does not always refer to an identical career point for each. In an attempt to overcome this difficulty, the authors create age-determined synthetic cohorts, and embark on a speculative investigation of a simple causal chain career model where occupational status at one point in time is a function of the immediately preceding occupational position (Blau and Duncan, 1967: 177-188). Although this model has certain ambiguities which were considered in more detail in subsequent analysis by Duncan and his associates, it does suggest that the influence of socioeconomic background factors upon occupational attainment decreases rather markedly as time in the labor force advances (Duncan, Featherman, and Duncan, 1972: 205-209).

Using the work of Blau and Duncan as a point of departure, more recently Featherman (1971) investigated a more complex career model incorporating lagged effects such that occupational status is not only a function of the prior occupation, but of other occupational positions held in the past. Exploiting longitudinal data from the Princeton Fertility Study, Featherman found relatively mild lagged effects, but when Kelley (1973) reconsidered these data he discovered that after adjusting for measurement error, even these weak historical influences tend to disappear. Regardless of these lagged effects, in Featherman's research and in Kelley's reanalysis, the decline in the effect of the background variables on current status is clearly apparent.

One of the key factors in both the lagged and causal chain models is the status of the occupation held upon initial entry into the labor force because it is one of the basic predeter- 
mining variables at the beginning of these career models.' Because of the central role played by the status of first job, it is our view that the behavior of this variable merits closer inspection, especially in regard to the differential effect of first job at differing points in the work career.

The position taken here is essentially similar to that of the human capital theorists, especially Mincer $(1970,1974)$ and Becker $(1964,1967)$, who view experience in the labor force as a valuable type of postschool investment or resource which accounts, in part, for earning differentials among the labor force. $^{2}$ In our view, work experience is an investment which tends toward reducing the relative importance of the initial point of entry into the occupational status hierarchy. The longer a worker remains active in the labor force-further away in time from the first occupation-the more work experience and related skills accrue to the worker such as on-the-job training. Many of these skills are transferable from job to job, thus they represent a marketable resource for the worker. As the worker continues in the labor market, the more this acquired experience affects current attainment, and concurrently, the less influential is the status of the first job. In other words, there is an increasing independency between current position and the initial entry point in the labor force. This is not, however, to claim that occupational status becomes increasingly indeterminant, but rather that current position becomes, to some degree, contingent upon the accumulation of labor experience, and those skills which are generated by exposure to the work environment. Our position is, then, that the influence of first job on current occupational attainment decreases, or decays, as time in the labor force advances. ${ }^{3}$ Consequently, there must be a corresponding increase in the relative importance of experience in affecting current position as time in the labor force accumulates.

In sum, we are postulating an interaction between labor force experience and status of first job on current occupa- 
tional position, but the form of this hypothesized interaction is unclear. In the next section we will consider three mutually exclusive, but not necessarily exhaustive, alternative models to describe this interaction, each of which implies a different dy namic career process.

\section{THE MODELS}

The most straightforward formulation is the Constant Decay (CD) model which posits that the influence of the first occupation's status on current occupational attainment declines at a constant rate during the work career. This relationship is graphically displayed in the first panel of Figure 1. This model implies that the loss in the influence of first job is an inverse linear function of time spent in the labor force. This seems unreasonable since such a relationship would require that the decline in the effect of first job during the initial five years of the career, say, is equivalent to the decline in the last five year period. We do not find this symmetrical aspect of the $C D$ to be appealing, but for the sake of conceptual completeness it is included here.

The requirements for the $C D$ model may be formalized in terms of restrictions placed on the derivatives of the relationship between time in the labor force, and the function linking first job with current status. Let $f(X)$ represent the effect of the status of first occupation upon current attainment, and let $\mathrm{T}$ be the number of years spent active in the labor force. The derivative of $\mathrm{f}(\mathrm{X})$ with respect to $T$ represents, then, a change in the first job-current position relationship given a change in the length of time spent in the labor force. The restrictions which can be imposed on this function are

$$
\begin{aligned}
& (d f(X) / d T)<0 \\
& \left(d^{2} f(X) / d T^{2}\right)=0 .
\end{aligned}
$$




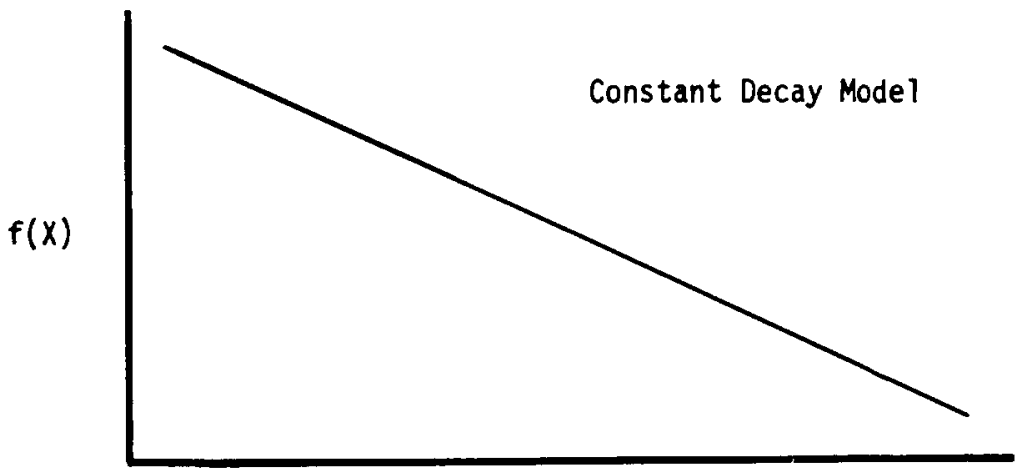

TIME IN LABOR FORCE

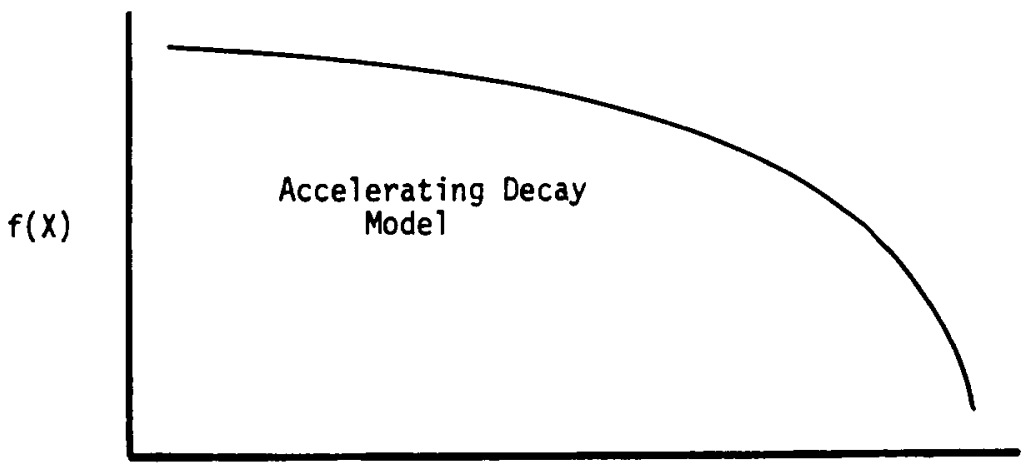

TIME IN LABOR FORCE

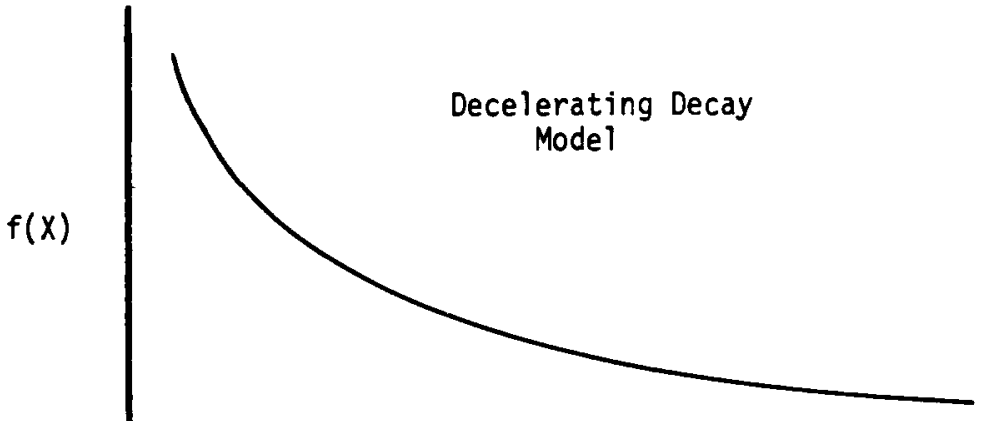

TIME IN LABOR FORCE

Figure 1. 
The second alternative is the Accelerating Decay (AD) model. This formulation suggests that the importance of the first job remains relatively substantial during the early periods in the labor market, but declines rather rapidly with increased work experience. This version has some appeal since it is reasonable to anticipate that after the initial years in the job market, a worker's first job ceases to be a significant factor to be assessed when considering future employment, or promotional, possibilities. This model also implies, however, that there is less return on work experience gained early in the career than experiences acquired later. That is, to the degree to which experience mitigates the effect of first job, this reduction comes only with much accumulated time in the labor force. Panel 2 of Figure 1 is a representation of the AD model. The restrictions placed on the derivatives of the function are

$$
\begin{aligned}
& (\mathrm{df}(\mathrm{X}) / \mathrm{dT}) \quad<0 \\
& \left(\mathrm{~d}^{2} \mathrm{f}(\mathrm{X}) / \mathrm{dT}^{2}\right)<0 .
\end{aligned}
$$

The last model is identified as the Decelerating Decay (DD) model, and it is presented in panel 3 of Figure 1. In this alternative the return on experience is greater early in the work career, and diminishes rapidly as time increases. As a result, the greatest decline in the effect of the first occupation on current job occurs during the first stages of the career, while the later periods are characterized by a decreased rate of decay in the importance of this initial job. It is noteworthy that if the causal chain career model is correct, the effect of first job would decline in a pattern consistent with the DD formulation. There is also some empirical evidence to suggest that this is a credible model. If the partial path coefficients from Featherman's (1971: 301) study of work careers and the partial paths from the 1970 Detroit Area Study work histories, as reported by Featherman (1973: 789), are plotted against time, the resultant 
curves provide support for this DD alternative. The restrictions on the derivatives for this model are

$$
\begin{aligned}
& (\mathrm{df}(\mathrm{X}) / \mathrm{dT})<0 \\
& \left(\mathrm{~d}^{2} \mathrm{f}(\mathrm{X}) / \mathrm{dT}^{2}\right)>0 .
\end{aligned}
$$

The major differences among these three models are clearly apparent from Figure 1. The AD model implies that there is a greater amount of status stability, vis-à-vis the relationship between first and current statuses, for the early periods than does the DD version. While there are many empirical studies (see Slocum, 1974: 211-239) which find large amounts of job instability in the first few years of work, this does not necessarily imply status instability, although the converse is true. Hence, the early status instability intrinsic to the DD model can only occur if there is corresponding job mobility, but we can not infer from the status stability of the AD model that there is corresponding job immobility.

While there are a variety of functions which will fulfil the restrictions imposed on the first and second derivatives of each conceptual model, there is a more economic strategy. We shall define a comprehensive form for our interaction

$$
f(X)=\lambda_{0}-\lambda_{1} T^{K}
$$

where $\lambda_{0}$ is the effect of the first job's status on current occupational attainment upon initial entry into the labor force; $\lambda_{1}$ determines the rapidity of decay as work experience advances; and $\kappa$ is a parameter which controls the shape of the decay curve. By permitting $(\kappa=1)$, the function is transformed into the constant decay model, but when $(\kappa>$ 1), equation 1 becomes the accelerating decay version, and lastly, if $(0<\kappa<1)$, we have the decelerating decay formulation. Hence, each of the three models can be represented by the proper selection of a value for $\kappa$. By estimating $\kappa$, then, it can be determined which of these 
formulations is the most reasonable in the sense that it provides the optimal fit for a given set of data.

One issue must be reconciled prior to launching on an empirical evaluation of the decay models-f(X) must be selected. Traditionally, current occupational status has been expressed as a linear combination of predetermining variables (see Blau and Duncan, 1967). As a first approximation, and in light of previous research, we choose to let $f(X)$ be represented by

$$
f(X)=Y=\alpha+\beta_{y X} X
$$

where $\mathrm{Y}$ is current status and $\mathrm{X}$ is the status of the first job. Thus, current position is held to be a simple linear function of first job. At a later stage of the analysis, a more sophisticated, and conceptually satisfying, formulation for $\mathrm{f}(\mathrm{X})$ will be employed.

\section{DATA AND MEASUREMENT}

Data for this investigation came from an area probability sample survey of heads of households conducted in two nonmetropolitan areas of Illinois during 1971. (See Summers et al., 1969, for details.) The data used in this analysis are from 833 employed nonfarm male heads of households under the age of 65. All respondents are white. In the 1971 survey, data were collected pertaining to the current occupation of the respondent, time spent in the labor force, first occupation, level of educational attainment, and father's occupation. Each of the occupational variables was coded into the detailed three-digit U.S. Census codes for occupations and industries. These codes were then translated into Duncan's (1961) socioeconomic index (SEI). Although the educational attainment and father's occupation variables have not entered into the discussion so far, their importance will be demon- 
strated shortly. The following operational definitions were employed in this analysis.

Current Occupational Status (Y)-SEI score for the respondent's 1971 occupation.

Status of First Job (X)-SEI score for the respondent's first full-time occupation after completing all formal education. In the interview schedule used in the survey, there was a set of screening questions designed to ensure that false starts in the labor force were eliminated from this item.

Labor Force Time (T)-the difference between 1971 and the year the respondent began his first full-time occupation. ${ }^{4}$

Father's Occupational Status (Z)-SEI score for the respondent's father's occupation when the respondent was sixteen years old.

Educational Attainment Level (W)-the number of years of formal education achieved by the respondent as of 1971 .

The labor force time variable (T) was collapsed into 10 five-year intervals ranging from $0-4$ to $45-49$ years in the labor force, and the 833 respondents were cast into cohorts according to the length of time spent in the labor market. The number of respondents in each of these ten synthetic cohorts is assembled in Table 1. Within each cohort, the linear regression of current occupational status $(\mathrm{Y})$ on status of first job (X) was computed. Hence, $\beta_{\mathrm{yx}}^{(\mathrm{i})}$ is understood to designate the estimated bivariate slope of this regression within the $\mathrm{i}^{\text {th }}$ synthetic labor force cohort. The results of these regressions are also presented in Table 1.

From this tabulation, an inverse, albeit nonmonotonic, trend does seem to exist in these bivariate slopes. The last row in the table gives the coefficients for the bivariate regression after pooling all 833 observations, thus ignoring intercohort differences. The slope for this pooled regression is 0.5833 , whereas the intercohort regression slopes range from 0.8441 for the first cohort to -0.2225 for the last. It is clear from these data that there is considerable variation in the effect of first job contingent upon the length of time spent in the labor force. 


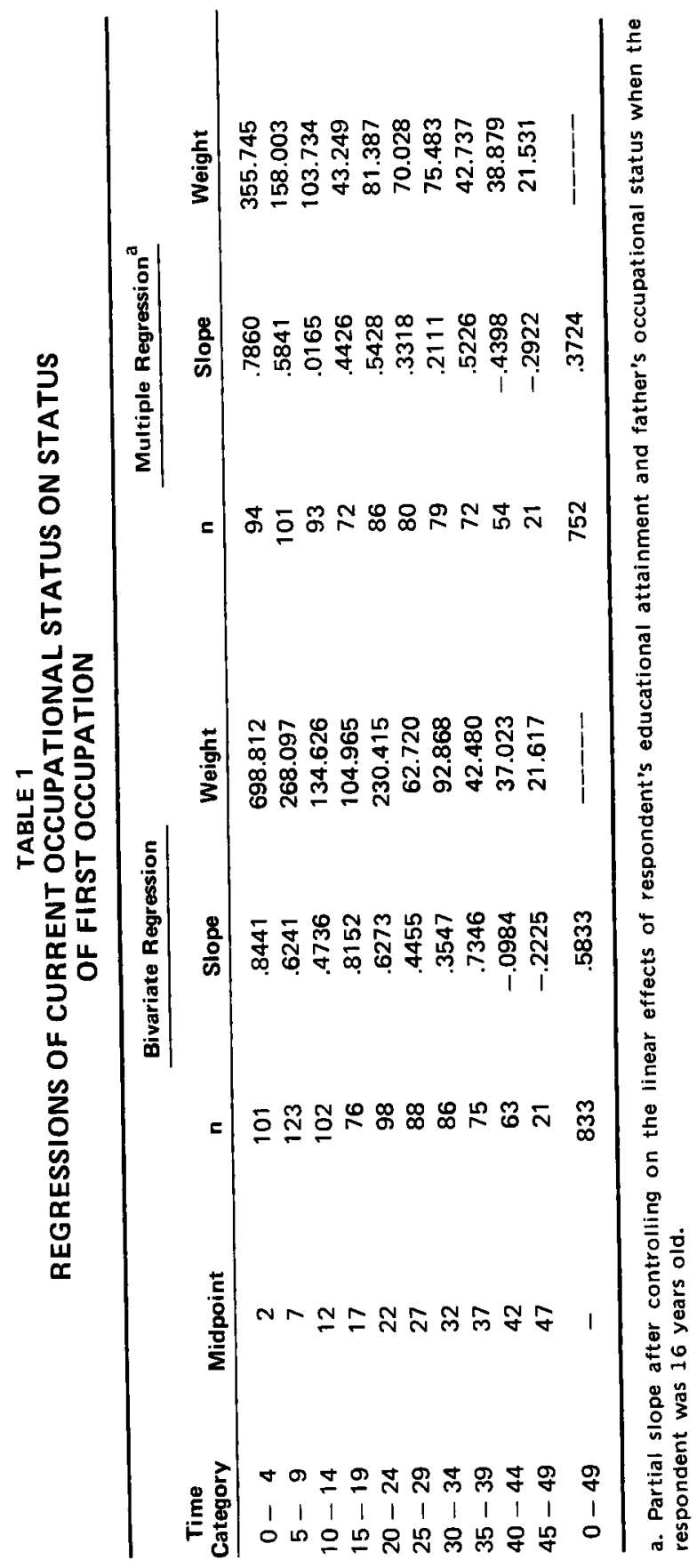


Since each of the $\beta_{y x}^{(i)}$ has a different sampling variance, each estimate should not be considered equally reliable. That is, there is variation in the precision of estimation of the cohort slopes which effectively curtails any simple crosscohort comparisons. To cope with this situation, all subsequent analyses were done with weighted data where each weight is the reciprocal of the sampling variation of the $i^{\text {th }}$ intracohort slope. This procedure ensures that the most reliable and precise estimates, those with the smallest sampling variances, have the most influence on the results.

As Blau and Duncan (1967: 179-188) point out, data such as these are amenable to two somewhat opposing interpretations. First, the differences in slopes could be the result of entering the labor force during different historical periods. For example, the men in the 45-49 cohort began their work careers between 1922 and 1926, while the youngest cohort entered the labor force between 1967 and 1971. It is possible that the observed intercohort variation in slopes is totally due to these groups beginning their careers under varying sociohistorical circumstances.

The second interpretation of these slopes is as synthetic longitudinal data on a single cohort. With this interpretation we take the labor force cohorts as a surrogate for actual long term longitudinal data on a single group of men who began work between 1922 and 1926. Unfortunately there is no clear, unambiguous way of determining which of these interpretations is correct. To further complicate the issue, these two interpretations are not necessarily mutually exclusive, and it is quite likely that our data may reflect some unknown mix of historical and cohort effects.

The cohort interpretation would be bolstered, however, if it were found that the effect of educational attainment on first job, the effect of father's status on first job, and the effect of father's status on educational attainment did not vary systematically among cohorts. Or in other words, if the cohort interpretation is to be believed, the interrelationships 
among these three background variables should be reasonably stable, barring sampling variation, across the ten cohorts.

To explore these hypotheses, the partial slope of the multiple regression of status of first job on education controlling on father's status, of status of first job on father's occupational status controlling on education, and the bivariate slope of education on father's status were computed within each cohort, then weighted by the reciprocal of the estimate's sampling variance.

If these relationships are stable across cohorts, there should not be any systematic trend in the estimated slopes. Utilizing a comprehensive model, incorporating nonlinear as well as linear components, no statistically significant, at the .05 level, cross-cohort patterns were found in the net relationship between father's status and first job, nor in the net relationship between father's status and educational attainment. It was found, however, that the dependency of first job on education was considerably greater for men in the more recent cohorts than those who had been in the labor force longer. This may be due to either a more reliable reporting of first job and education by those in the younger cohorts, or the result of historical changes in the relationship between occupational attainment and educational achievement. In the latter instance, this finding suggests that the cohort interpretation may not be totally convincing, and that it must be adopted with due caution.

\section{ANALYSIS}

Let us assume that a true pattern does exist in the influence of the status of first job on current occupational attainment (the bivariate slopes presented in Table 1), and that the anomalies in these data are the result of random disturbances. This assumption is quite reasonable considering that if a true trend is present in the population, coefficients 
computed from sample data would vary about this population trend in a random manner. Taking the weighted $\beta_{y x}^{(i)}$,s as the dependent variable, and the midpoints of the labor force cohorts as the independent variable, a stochastic model was estimated

$$
\hat{\beta}_{\mathrm{yx}}=\lambda_{0}-\lambda_{1} \mathrm{~T}^{\kappa}+\epsilon
$$

where $\epsilon$ is a normally distributed disturbance with a zero expectation and constant variance. It is assumed that it is this disturbance which is responsible for the irregularities in the observed bivariate slopes.

The estimated value of $\kappa$ was obtained through an iterative procedure. First, $k$ was initialized at some value, say $\kappa^{*}=0$, then the error sum of squares $\left(\mathrm{SSE}_{\mathrm{i}}\right)$ was determined by a generalized least squares solution to the weighted regression of $\hat{\beta}_{\mathrm{yx}}$ on $\mathrm{T}^{\kappa}{ }^{*}$. Next, $\kappa^{*}$ was incremented by some small value, say $|0.001|$, then a new $\left(\mathrm{SSE}_{\mathrm{i}+1}\right)$ was computed. If $\left(\mathrm{SSE}_{\mathrm{i}+1}<\mathrm{SSE}_{\mathrm{i}}\right)$, the cycle was repeated until a value of $\kappa^{*}$ was found which minimized the error for the regression, and this value was taken for the final estimate of the parameter. $\kappa^{*}$ was varied over a sufficient range to make it unlikely that the final estimate was based on a local, and not global, minimum error sum of squares. Once an estimate of $\kappa$ was derived, the parameters $\lambda_{0}$ and $\lambda_{1}$ were determined in straightforward generalized least squares fashion.

By this procedure, it was found that values of $\hat{\kappa}$ in the interval

$$
1.871 \leqq \hat{\kappa} \leqq 1.873
$$

minimized the error variance for the regression. In other words, there was no substantial change in the error sum of squares for $\hat{k}$ 's falling within the limits of this interval, so a point estimate of $\kappa$ was taken as the midpoint of the interval. $\hat{\kappa}=1.872$. 
Taking $\hat{\kappa}=1.872$, the remaining parameters were computed giving us this final solution (standard errors in parentheses):

$$
\begin{aligned}
\hat{\hat{\beta}}_{\mathrm{yx}} & =0.7833-\left(0.5993 / 10^{3}\right) \mathrm{T}^{1.872} \quad \mathrm{R}^{2}=0.6173 \\
& (0.0574)\left(0.1669 / 10^{3}\right)
\end{aligned}
$$

where $\hat{\hat{\beta}}_{\mathrm{yx}}$ is the bivariate slope predicted by the general decay function. Each of the coefficients is significant at the .01 level.

It might be argued that $62 \%$ explained variance is inadequate in the context of aggregate curve fitting, yet it would seem clear that the observed decay trend does exist, and is not a product of capricious random variation. However, with $38 \%$ unexplained variance, something appears amiss, and the most likely culprit is that the cohort interpretation of the data is not completely justified. A close inspection of thə residuals from equation 4 revealed that the largest deviation, nearly twice as great in absolute value as the nearest competitor, was for the 35-39 year cohort which is composed of men who entered the labor force during the Depression period 1932-1936, and were, most likely, out of the civilian labor force for the duration of the war years, 1942-1945.

If the basic stochastic model given in equation 3 is re-estimated without the Depression cohort, the results are very similar to those presented in equation 4 :

$$
\begin{aligned}
\hat{\hat{\beta}}_{\mathrm{yx}}=0.7825-\left(0.3531 / 10^{3}\right) \mathrm{T}^{2.065} & \mathrm{R}^{2}=0.7550 \\
& (0.0482)\left(0.7603 / 10^{4}\right)
\end{aligned}
$$

except that the proportion of explained variance is considerably larger. This suggests that the general accelerating decay trend implied in equation 4 is rather insensitive to the presence of the Depression cohort, and that our conclusions 
are not seriously jeopardized by this group of men. We believe that the presence of possibly historically unique outliers, such as the 35-39 year cohort, can be interpreted as "noise" in the data, but that it does not completely obviate the broader implication that the gross effect of first job decreases, at an accelerating rate, with increased labor force experience. In order to fully evaluate the implications of the estimated trend, it will be necessary to make a more detailed inspection of the coefficients in equation 4.

By setting the left-hand side of equation 4 to zero, it can be determined at what point in time the status of first job ceases to influence current status attainment. It was found that when $T=46.2$ years, the predicted slope was null. Hence, after approximately 46 years in the labor force, the initial point of entry is irrelevant to current position. Based on the regression of age on time in the labor force for all 833 men, our prediction equation suggests that by age 63 first job is unrelated to current position. This is, of course, empirical confirmation of the obvious: by the time workers are preparing to retire at the end of their active work life, the initial status is no longer an issue of practical interest. However, it is comforting to know that the empirical model gives predictions consistent with our intuitive understanding of the labor market.

Given that the estimated value of $\kappa$, with or without the Depression cohort of men, is considerably larger than unity, we have evidence suggesting that the decay trend follows more closely the accelerating model as opposed to the other two alternatives. Our findings would imply that there is a relatively large degree of status consistency, or stability, between first occupation and current position early in the work career, but that this stability declines during the later periods.

Rarely, however, is there interest only in the effect of first job on current status. More typically, socioeconomic background variables are also included in the model. Two of these 
which appear frequently in the literature are the respondent's educational achievement and father's occupational status. Education may immediately affect a worker's current status through the acquisition of employable technical abilities, or as a necessary requisite for job promotion. But also, to the degree to which education, and background status, represent an identifiable constellation of social skills and behavioral traits, it may be expected that these factors will have significant effects during the work career. In this context, educational achievement may represent the certification of a generalized skill level which can be expected to have long term occupational payoffs, rather than the manifestation of any specific vocational training. We will modify the analysis at this juncture to permit incorporation of these additional background variables into our explorations.

Within each cohort we computed $\hat{\beta}_{\mathrm{yx} \cdot \mathrm{zw}}$, the partial slope of the regression of current status (Y) upon first job (X), after controlling, on the linear, and additive, effects of father's occupational status $(Z)$ and the respondent's educational attainment $(W)$. These partial slopes and their weights, are also assembled in Table 1. As can be seen from this tabulation, there appears to be some general decay trend in the magnitudes of these partial slopes, but this pattern is far from being strictly monotonic. Again assuming that there is an underlying trend that is disguised by random disturbances, the following model was fitted to the partial slopes,

$$
\hat{\beta}_{\mathrm{yx} \cdot \mathrm{zw}}=\lambda_{0}-\lambda_{1} \mathrm{~T}^{\kappa}+\epsilon \text {. }
$$

The procedure used to derive the estimates of the parameters in equation 9 was comparable to those outlined previously, and it was discovered that $\hat{\kappa}=0.120$ would minimize the error for the regression. The least squares estimates of $\lambda_{0}$ and $\lambda_{1}$, and their standard errors, were found to be 
[388] SOCIOLOGY OF WORK AND OCCUPATIONS

$$
\begin{aligned}
\hat{\hat{\beta}}_{\mathrm{yx} \cdot \mathrm{zw}}= & 2.3375-(1.4337) \mathrm{T}^{0.120} \quad \mathrm{R}^{2}=0.5925 . \\
& (0.5500)(0.4204)
\end{aligned}
$$

Each of the coefficients is statistically significant at the .01 level. This solution explains $59 \%$ of the variance, but if the Depression cohort of men is deleted from the analysis, the estimated relationship becomes

$$
\begin{aligned}
\hat{\hat{\beta}}_{\mathrm{yx} \cdot \mathrm{zw}}= & 1.0365-(0.1954) \mathrm{T}^{0.457} \quad \mathrm{R}^{2}=0.6693 \\
& (0.1659)(0.5193 / 10)
\end{aligned}
$$

which is consistent with the results given in equation 7 . This reinforces our position that our conclusions are not compromised by the inclusion, or exclusion, of the Depression cohort.

Whereas the accelerating decay model was found to fit the bivariate slopes, the magnitude of the $\hat{\kappa}$ 's from equations 7 and 8 strongly imply the decelerating decay version for the influence of first job on current status after controlling for the effects of education and father's occupational status. These differences are made clear by inspecting the predicted relationships.

The very pronounced difference between the decay trends estimated by the bivariate and partial slopes is revealed in Figure 2 which plots the predicted influence of first job against the number of years spent in the labor force. As can be seen from this graph, there is minimal decline in the gross effect of first job on current status during the earlier periods, and in fact, there is less than $10 \%$ decay in this gross effect during the first thirteen years in the labor force. This certainly implies that the initial point of entry into the marketplace plays a continued role in affecting current status even after several years of work experience. Hence, there is considerable status consistency during this early period. 


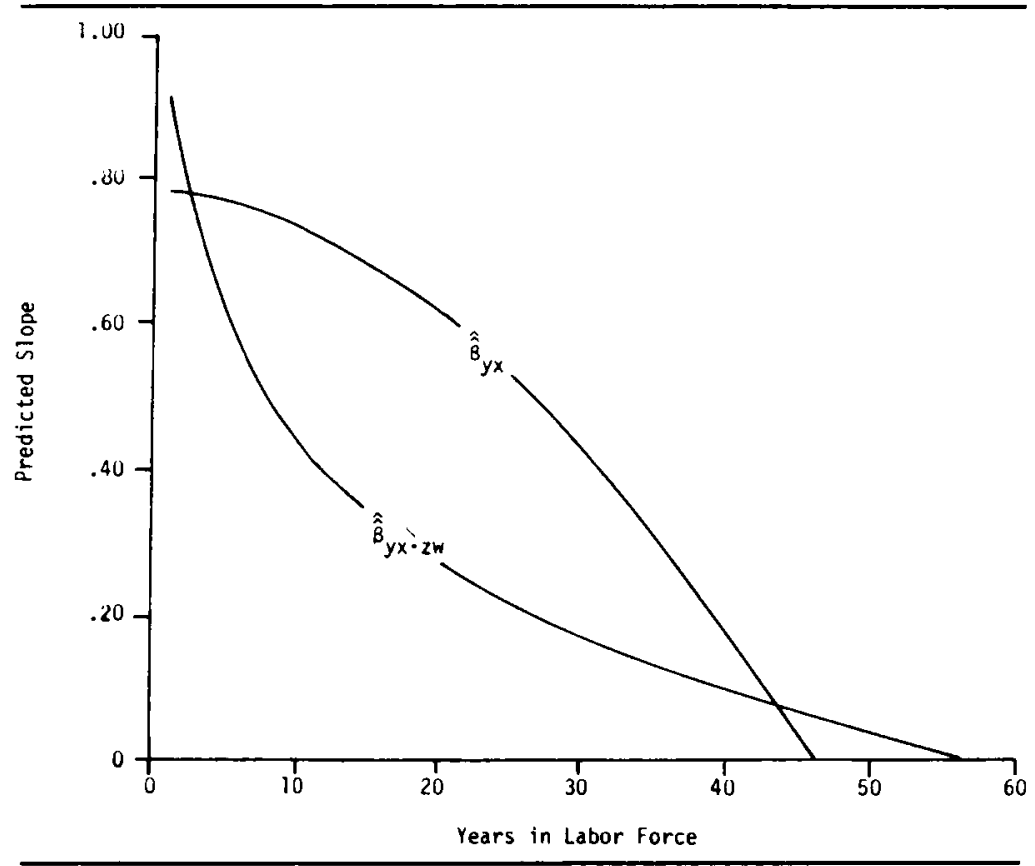

Figure 2.

If, however, father's status and educational attainment are controlled, a rather different picture emerges. Specifically, the net effect of first job decreases dramatically early in the work career, and by the time the worker has accumulated ten years' work experience, there is more than a $50 \%$ decline in the effect of first job. This finding is consistent with Kelley's (1973) view that status transitions follow a causal chain. It is also consistent with the findings of many others, e.g., Lipset's and Bendix's analysis of the 1949 Oakland Labor Mobility Survey, that there is a large amount of job instability during the early years in the labor force. It would seem, then, that from the marked differences between the bivariate and partial curves that much of the apparent continuing influence of first job is actually due to background status and education, and not to first job per se. 
Throughout the analysis differences among workers as to the type of job held have been ignored. Essentially this means that pipefitters and dentists, say, have been treated equally, excepting for obvious discrepancies in occupational status. The clear differences in job recruitment, typical career tenure, educational certification requirements, degree of professionalization and unionization, and so forth have been ignored. It would seem intuitively reasonable to anticipate that the relationship between labor force entry and current occupational status may vary by type of occupation, and there is no a priori reason to believe that the career contingencies of workers are not qualitatively different dependent on the type of labor in which they are engaged.

Although we lack a sufficient data base from which to investigate in detail this hypothesis, we took an exploratory step, albeit unrefined, in that direction by partitioning the 833 men according to their current occupation into a group of 370 white-collar workers and another group of 463 blue-collar workers, and then redoing the analysis. ${ }^{5}$ While having these small numbers of men cast into ten labor force cohorts results in a rather weak empirical foundation, there are a number of highly interesting and suggestive findings.

Regardless of whether interest is on the gross effect of first job, the bivariate slopes, or on the net influence, the partial slopes, we found that in the white-collar group the effect of first job follows a decelerating decay form. On the other hand, in the blue-collar occupations it was discovered that both the gross and net effects of first job on current status correspond to the accelerating decay model, although these estimated relationships are not far from being linear. ${ }^{6}$

Further, while the influence of the first job decreases at a greater rate early in the career for white-collar workers, this influence persists longer than for men in the blue-collar occupations. These tentative findings are consistent with the view that occupants of white-collar positions experience greater amounts of status instability early in their careers 
than do blue-collar workers, yet the residual influence of the initial point of entry seems to continue longer into the latter stages of the work career. It is not possible, however, to differentiate between characteristics of individuals versus characteristics of occupations. Thus it is not known whether the observed instability is due to a propensity for white-collar workers to have more "false starts" in the labor force before entering a more stable career pattern, or whether only high turnover jobs are available to future white-collar occupants early in their career.

We are aware, however, that there is more variation in regard to status among the occupations aggregated into the white-collar category than those grouped under the bluecollar heading, and this heterogeneity could be responsible for the apparent greater status stability among this latter category of workers. Nevertheless, quite clearly there are pronounced differences in the predicted relationship between entry point and current status depending on whether the current job falls into one of the white-collar or blue-collar classifications.

\section{CONCLUSIONS}

Three alternative models were presented to represent the decreased importance of the status of first job on current occupational status over time: (1) constant decay model; (2) accelerating decay model; and (3) the decelerating decay model. Each of these is a special case of a general three-parameter function,

$$
f(X)=\lambda_{0}-\lambda_{1} T^{K}
$$

where $f(X)$ is the relationship between first occupation and current job; $\lambda_{0}$ is the effect of first job upon initial entry in the labor market; $\lambda_{1}$ controls the rate of the decay curve; $T$ is 
the length of time spent in the labor force; and $k$ is a parameter which determines whether the decay is linear, convex, or concave.

Using occupational and background data on 833 employed nonfarm males cast into ten synthetic cohorts to explore these various formulations, it was found that the accelerating decay model optimally described the gross effect of first job, but when education and father's status are controlled, the influence of first job followed the decelerating decay pattern more closely than the other two versions.

While there is some evidence which renders the cohort interpretation not totally convincing, the analysis indicates that the net influence of first occupation upon subsequent occupational status is seriously attenuated by the length of time spent in the labor force. As the time elapsed between first job and current position increases, the effect of the initial entry point is diminished, and this erosion is most severe during the early periods of the work career. By the time the worker has been actively employed for four years, first job has already lost over $25 \%$ of its initial influence, and this decline continues until the worker exits the labor force. Hence, labor experience gained early in the career is more important, in the sense of mitigating the influence of first job, than experiences acquired later.

It was suspected, however, that the first job-current status relationship might be contingent upon the occupational classification of the worker. An exploratory analysis based on a blue-collar-white-collar distinction tends to support this position. There is some limited evidence which suggests that the decelerating decay model holds for both the gross and net effects of first job in the white-collar categories, while the blue-collar workers seem to be characterized more by the accelerating decay formulation. The implication is that there is greater early career status instability among the whitecollar workers than among those in the blue-collar positions. This does not, however, suggest that those in blue-collar 
occupations have greater job stability, but rather that any early job changes among blue-collar workers are more homogeneous vis-à-vis the occupational status hierarchy.

Although there is evidence that the effects of first job erodes with time, we are still left with the problem of specifying those factors which become more important in influencing occupational status as labor force experience accumulates. In this paper we suggested that the length of exposure to the work environment represented acquired work experience, a valuable resource. Hence, time became a surrogate for the unmeasured variables encompassing the global notion of experience. It would be more satisfying to have direct measures of these postulated acquired skills, and incorporate these variables directly and explicitly in the analysis.

In any event, it seems clear, based on the results obtained here, that status models which do not explicitly incorporate experience in the labor force as an integral part of the model may suffer a serious specification error. By treating a set of observations as if all respondents are homogeneous in regard to career tenure, and thus neglecting the time interaction concept presented here, the model may underestimate the effect of first job during the early years in the career, and overestimate this influence for the later stages. There is also evidence that aggregating respondents over occupational classifications can distort the complexities of career contingencies.

\section{NOTES}

1. In Featherman's (1971) study the "first" occupation is taken as the occupation at marriage. Although Featherman's "occupation at marriage" is not identical to Blau and Duncan's "first job," they are sufficiently similar to be comparable. 
2. Plotting a different tack, Sorensen (1974) argues for a model of job shifts which holds that changes in status are due to the status of the old job and the total amount of resources mustered by the individual. For Sorensen, these resources are a constant throughout the career, hence he takes a dramatic departure from the human capital position, and the one presented here, which posits that one of the chief human resources is cumulative labor experience.

3. A second variable, the length of time remaining in the worklife, is somewhat related to time in the labor force and might be introduced into the model. Since the worklife is finite, a person who begins his or her first job at age 50 has many fewer years in which to develop a stable career than a person age 20 . It is reasonable to believe that occupational processes will be affected by the amount of time remaining over which social investments (training, and so forth) can be amortized. This may be especially germane when considering career models for women.

4. Perhaps a preferred operationalization would make two alterations: (1) to consider discontinuities in employment so that the variable would be the length of time continuously employed; and (2) to measure from the beginning date of the first job to the beginning date of the current job. Although limitations in our data prevent us from implementing these suggestions, these additional refinements would improve the operationalization of the concept "experience."

5. The white-collar category was composed of four occupational groupings: professional, technical and kindred; managers, officials, and proprietors; clerical and kindred; and sales workers. The blue-collar occupational classification was a combination of five groupings: craftsmen, foremen, and kindred; operatives and kindred; private household workers; service workers; and laborers.

6. For the white-collar group of men the estimated value of $k$ was 0.001 for both the bivariate and partial slopes $\left(R^{2}=0.8275\right.$ and $R^{2}=0.6097$ respectively). For the blue-collar workers, we found that $\hat{\kappa}$ was 1.262 for the bivariate slopes $\left(R^{2}=0.7204\right)$ and 1.043 for the partials $\left(R^{2}=0.6069\right)$. It should be noted that the percentage of explained variance within each occupational category is higher than the percentages from the aggregated data, equations 4 and 7 . This certainly suggests that not disaggregating by occupational grouping can lead to misleading and distorted results.

\section{REFERENCES}

BECKER, G. S. (1967) Human Capital and the Personal Distribution of Income. W. S. Woytinsky Lecture 1. Ann Arbor; University of Michigan, Department of Economics.

-..-(1964) Human Capital. New York: National Bureau of Economic Research. BLAU, P. and O. D. DUNCAN (1967) The American Occupational Structure. New York: John Wiley.

DUNCAN, O. D. (1961) "A socioeconomic index for all occupations," pp. 109-138 in Albert J. Reiss, Jr. et al. Occupations and Social Status. New York: Free Press. 
--- D. L. FEATHERMAN, and B. Duncan (1972) Socioeconomic Background and Achievement. New York: Seminar.

FEATHERMAN, D. L. (1973) "Comments on models for the socioeconomic career, Amer. Soc. Rev. 38 (December): 785-790.

-- (1971) "A research note, a social structural model for socioeconomic career." Amer. J. of Sociology 77 (September); 293-304.

KELLEY, J. (1973) "Casual chain modeis for the socioeconomic career." Amer. Soc. Rev. 38 (August); 481-493.

MINCER, J. (1974) Schooling, Experience, and Earnings. New York: National Bureau of Economic Research.

-- (1970) "The distribution of labor incomes: a survey." J. of Econ. Literature 8 (March): 1-26.

SEWELL, W. H., A. O. HALLER, and A. PORTES (1969) "The educational and early occupational attainment process." Amer. Soc. Rev. 34 (February): 82-92.

SLOCUM, W. L. (1974) Occupational Careers. Chicago: Aldine.

SORENSEN, A. B. (1974) "A model for occupational careers." Amer. J. of Sociology 80 (July): 44-57.

SUMMERS, G. F. et al. (1969) Before Industrialization: A Social System Base Study of Rural Area. Bulletin 736. Urbana: Illinois Agriculture Experiment Station, University of Illinois. 